\title{
Engaging Indigenous Communities in Higher Education: An Analysis of Collaboration and Ownership in Alaska Native Teacher Preparation
}

\author{
Lenora "Lolly" Carpluk \& Beth R. Leonard
}

\begin{abstract}
In 2008, our institution was awarded an Office of Indian Education preservice teacher preparation grant intended to increase the number of Alaska Native/ American Indian teachers in Alaska. Our research examines grant objectives and outcomes, specifically related to the institution's stated focus on "culturally responsive teacher preparation" and "preserving and advancing" Alaska Native languages and cultures. We also explore challenges and opportunities encountered during the development of a cultural mentoring community for Alaska Native pre-service teachers, facilitated through collaboration with two Alaska Native teacher community organizations. Our work is informed by foundational literature in Indigenous culture-based pedagogy (Demmert \& Towner, 2003), Indigenous higher education (Brayboy, 2012), and culturally responsive/ culturally relevant pedagogy (Ladson-Billings, 1994). Decolonizing methodologies and TribalCrit (Castagno, 2012) are particularly significant in our analysis, as the institution's mission, vision, and strategic directions initiatives appear to be at odds with outcomes that suggest a continuation of top-down, colonized practices that perpetuate marginalization of Alaska Native students.
\end{abstract}

KEYWORDS Indigenous education; Indigenous pedagogies; teacher preparation; culturebased education

In 2008, the University of Alaska Fairbanks School of Education (SOE) was awarded an Office of Indian Education pre-service teacher preparation grant intended to increase the number of Alaska Native/American Indian teachers in Alaska. Our research examines grant objectives and outcomes, specifically related to the institution's stated focus on "culturally responsive teacher preparation" and "preserving and advancing" Alaska Native languages and cultures. We also explore challenges and opportunities encountered during the development of a cultural mentoring community for Alaska Native pre-service teachers, facilitated through collaboration with two Alaska Native teacher community organizations. Our work is informed by foundational literature in Indigenous culture-based pedagogy (Demmert \& Towner, 2003) and Indigenous higher education (Brayboy, 2012), and also scholarship that speaks to culturally responsive, relevant and sustaining pedagogy (Ladson-Billings, 1995; Paris, 2012). Decolonizing (Battiste, 2013) and Indigenous methodologies (Wilson, 2009) including TribalCrit (Brayboy, 2005; Castagno, 2012) is particularly significant in our analysis, as the institution's mission, 
vision and strategic directions initiatives appear to be at odds with outcomes that suggest a continuation of top-down, colonized practices that perpetuate marginalization of Alaska Native students in higher education.

We begin with an overview of the Alaskan educational context, followed by a summary of grant objectives, including how our background experiences in K12 and higher education informed the research orientation. Also significant to the research and program refinement was the community engagement emphasis, an approach that made the Alaska Native Teacher Preparation Project (ANTPP) different from past teacher preparation grants held by SOE. We then discuss pre-service teacher preparation at our institution. Student voices from interviews and field notes support our conclusion as to the success of the partnerships with Alaska Native teacher communities. We close with an overview of evaluator recommendations for refining Alaska Native teacher pre-service programming and summary commentary on the Indigenous space currently occupied by our institution and its publicly stated responsibilities regarding Alaska Native people/communities.

\section{Native Teacher Representation: The Alaskan Context}

From 1970 to 2014 (44 years), 172 Alaska Natives—or about 4 per year-earned teacher certification through the programs we reviewed. ${ }^{1}$ At that rate, the programs could never produce enough new rural-resident and Alaska Native teachers to increase their representation in Alaska's rural schools. And several of those programs have now been discontinued. (Leary et. al., 2014, p. 4)

At the time the ANTPP proposal was in draft (2008), SOE had graduated 408 Alaska Native teachers since the rural Bachelor of Education program began in 1970 (Barnhardt, 2002). Despite pre-service education initiatives in the University of Alaska system, critical disparity and equity challenges remain for the State of Alaska in terms of supply and demand, including the diversity of its teaching workforce in relation to the diversity of the student body. Alaska is divided into 56 educational districts; "Regional Educational Attendance Areas" (REAAs) were established for smaller communities without a formal "borough" structure. Within the state, Alaska Natives comprise only five percent of the teaching force, while approximately $24 \%$ of K-12 students are Alaska Native ( $80 \%$ in rural districts), a disproportionately large gap. Almost $90 \%$ of teachers in the State are White. In addition to diversity disparities in the teaching force, teacher and administrator turnover continues to be a major challenge. During the years 2008-2012, about 64\% of Alaska's teachers came from outside the State. Further research from the University of Alaska Anchorage's Center for Education Policy Research (CAEPR) finds that "annual teacher turnover rates vary hugely among rural districts, ranging from a low of $7 \%$ to over $52 \%$, while urban districts have turnover rates that are generally lower and more similar, from about $8 \%$ to just over 10\%" and "among teachers with less than

\footnotetext{
1 Not all Alaska Native graduates were supported by teacher preparation grants.
} 
10 years of experience, those who prepared to be teachers in Alaska have much lower turnover rates than those from Outside" (Hill \& Hirschberg, 2013). The 2014 report by CAEPR lists a higher percentage of outside teachers-74\%, an increase of $10 \%$ from the 2012 statistics. Thus, most Alaska Native students will not have teachers that share similar backgrounds and experiences, necessitating culturally responsive teacher preparation that includes a critical understanding of Alaska Native worldviews and pedagogies (Lipka, Mohatt, \& Ilutsik, 1998; Ongtooguk, 2003).

\section{"Preparing K-12 Educators For This...Diverse State":}

[UAF SOE] faculty and staff strive to model, in their interactions with candidates at both the pre-service and graduate levels, the three critical characteristics that our candidates embody when they leave the program: professional, culturally responsive, and effective. These characteristics form the basis for our graduates' continued professional development and the formation of healthy and respectful relationships with their students, families and communities in which they live and work. ...In this spirit, the School of Education is committed to preparing and retaining the best possible K-12 educators for this far north, geographically, culturally and linguistically diverse state. (https:/ / sites.google.com/a/alaska.edu/soe-home/ accessed September 14, 2015).

The UAF School of Education includes BA and MEd programs in elementary and secondary education accredited through the Northwest Commission on Colleges and Universities, and the Council for the Accreditation of Educator Preparation ${ }^{2}$ (formerly the National Council for the Accreditation of Teacher Education). SOE requires that students "understand how the historical, political, economic, and social factors are interrelated and impact culturally responsive education and the issues of access and equity in Alaska's schools" (University of Alaska Fairbanks, 2013) and "have deep understandings of academic and pedagogical knowledge, the cultural, environmental and emotional contexts of children; and the cultural and linguistic backgrounds that reflect the diversity of the students in the community (University of Alaska Fairbanks, 2012)."

Conceptual methodologies and strategies to promote student success for Indigenous students and students of color have been discussed extensively in the literature. Sources relevant within Alaska Native higher education context include "A Yupiaq Worldview" (Kawagley, 2012); "Transforming the culture of schools: Yup'ik Eskimo examples" (Lipka et. al, 1998); Delpit's discussion of her experiences at UAF in "Other people's children: cultural conflict in the classroom" (2006), and "Resisting diversity: An Alaskan case of institutional struggle (Gilmore, Smith \& Kairaiuak, 2004). Prevalent concepts and theoretical constructs include "culturally-responsive," "culturally-compatible," "culturally-relevant," culturally-appropriate," "culturally-sensitive," and "culturally-congruent." Most recently, Paris' (2012) "culturally-

${ }^{2}$ Formerly the National Council for the Accreditation of Teacher Education (NCATE). 
sustaining pedagogy" extends previous theoretical perspectives "to perpetuate and foster... linguistic, literate, and cultural pluralism as part of the democratic project of schooling” (p. 93). Scholars-of-color, Indigenous and non-Indigenous scholars continue to sanction multicultural, anti-racist, social justice pedagogies as valid pathways to academic success, critical thinking, and cultural competence (Au, 2009; Gay \& Kirkland, 2003). However, coursework that facilitates "deep understandings" of culture, worldview and diversity requires a programmatic commitment beyond the one diversity-focused course required in the elementary program (Leonard, 2013) at that time. ${ }^{3}$ In the next sections we provide an overview of the project objectives, research questions, and student commentary.

\section{The Alaska Native Teacher Preparation Project}

For forty years, the UAF SOE has striven to refine its efforts to bring Alaska Native educators into professional positions in classrooms, administrative roles, and university positions...ANTPP will extend these efforts by creating a cohort of new Alaska Native educators who will accept the explicit challenge of not only advancing their own careers, but also investigating and creating ways that they, and their communities, can impact traditional public school and university education systems (Madsen \& Brayboy, 2007)

Responding to the demand for more Alaska Native teachers, the Alaska Native Teacher Preparation Project (ANTPP) proposal was initially drafted by Eric Madsen, a former dean of the University of Alaska Fairbanks (UAF) School of Education (SOE), and President's Professor of Education Bryan Brayboy, a prominent Lumbee scholar. During the drafting process, Madsen and Brayboy asked Leonard (Deg Xit'an Dena/Athabascan) to review the proposal and serve as the principal investigator (PI). The grant application was successful and was supported for four years by the Office of Indian (OIE) Education, a program within the Office of Elementary and Secondary Education, and overseen by the U.S. Department of Education. Following the award of the grant, Madsen and Leonard recruited Carpluk (Yup'ik) as the project coordinator in a term-funded faculty position. ${ }^{4}$ Caitlin Montague-Winebarger, then an interdisciplinary $\mathrm{PhD}$ student was hired as a research assistant as her investigation into pre-serve teacher education closely aligned with the project focus. ${ }^{5}$ Malia Villegas (Alutiiq/ Sugpiaq) and Susan Faircloth (Coharie) agreed to serve as project evaluators. Unique aspects of the grant included both community participation of the Alaska Native teacher organizations, and the major role of Alaska Natives/American Indians in administering grant operations and objectives.

\footnotetext{
3 These are part of the SOE Education requirements: "Foundation Coursework and Field Experience" (BA Elementary Education degree checklist https://sites.google.com/a/alaska.edu/soe-elementary/ba/degree_requirements)

4 Carpluk was then working as director of Future Teachers of Alaska, a University of Alaska Statewide program designed to recruit high school students into the teaching profession.

5 Winebarger completed her degree in 2012 - her dissertation is titled "That's a bard question": Undergraduate students talk about culture (unpublished doctoral dissertation; University of Alaska Fairbanks).
} 
The majority of grant funding provided financial assistance to the qualified pre-service Alaska Native/American Indian teachers. As is the case for Office of Indian Education professional development projects, in addition to requirements regarding academic placement (junior level) and good standing, participants needed proof of tribal membership or certificate of Indian blood (CIB). Student support included a monthly stipend, tuition, fees, books, childcare, laptop computer, Praxis test fee payment, induction services (assistance for first year teachers), and cultural mentoring support.

We learned that the financial support was not sufficient for the year-long internship and did not adequately meet all the students' financial needs. Although stipends were provided, they were not necessarily provided in a timely manner. Often students had to wait (especially during the first semester as a grant-funded participant), and this presented hardships for the students and their families. The application process required some coordination as the SOE and OIE had their own pre-set guidelines and criteria for qualification. The Office of Indian Education had guidelines for their grant applications, evaluation measures and basically their own agenda, (i.e., "someone else's agenda" as stated in Cornell \& Kalt, 2006) that we had to follow to administer the grant. Although the grant included its own goals and objectives, a timeline of activities, and signed consortium agreements from partners on their roles and responsibilities, we were still limited by Office of Indian Education's guidelines and the UAF SOE criteria for education interns. Upon graduating from the program, participants were required to accept a teaching position in a school or district with at least 5\% American Indian (AI) or Alaska Native (AN) student enrollment (remaining in a district with the minimum percentage for as long as they were supported as a student in the program) as part of their "payback" agreement with OIE.

Through project activities and research, staff actively investigated aspects of culturallyresponsive pedagogies in both the mainstream teacher preparation program, as well as those engaged through the Indigenous Education Institutes designed by Carpluk and members of the Alaska Native teacher organizations. ANTPP's research paradigm was inspired by the work of Indigenous scholars and researchers involved in collaborative, community-based and participatory approaches (St. Denis, 1992). Staff submitted an Institutional Review Board (IRB) proposal in 2009, which was approved as a "program evaluation and assessment" research project that included student-written reports (required by the grant), field notes maintained by staff, and interview data from students and consortium partners. Student and consortium partner participation in interviews was strictly voluntary. Our interview questions included:

- What are effective methods of preparing AI/AN teachers?

- What support systems are needed to ensure the success of undergraduate education students and first year teachers?

- Do SOE programs fulfill the needs of AI/AN teacher candidates?

- What needs to be improved or changed? 
Our overarching questions related to community engagement criteria included:

- What does it mean to engage community in higher education?

- How are collaboration and engagement defined, and by whom?

- What are the benefits of collaborative work with communities? Are collaborative efforts a "one-way street" or an authentic sharing of time and resources that provide benefits beyond the entities involved?

\section{Alaska Native teacher mentors: Indigenizing pre-service teacher preparation}

...two Alaska Native Educators Associations and the five rural Community Campuses (University of Alaska Fairbanks, undated) have entered into Consortium Agreements under which they will help SOE faculty critically examine its teacher preparation programs toward improving their effectiveness in preparing AN/AI teachers to work with all students, but particularly with AN/AI students. (Madsen \& Brayboy, 2007).

SOE has held several past grants that focused on pre-service education for Alaska Native teachers; project partners on these previous grants often included one or more school districts. Although Alaska Native community members often serve on school district advisory boards, Alaskan school districts are largely administered by non-Native personnel. To ensure Alaska Native involvement in the project, ANTPP engaged a community of scholars and educators beyond school district levels, specifically, the Association of Interior Native Educators (http:/ / www.ainealaska.org/), and the Alaska Native Education Association, a statewide organization with representatives from each of the Alaska Native teacher associations (see Carpluk, 1997 for the history and descriptions of these initiatives). In addition to the School of Education, university partners included the College of Rural and Community Development (CRCD) and its affiliated rural campuses. During the project period, CRCD was overseen by the former (and late) Vice Chancellor Bernice Joseph, and it bears recognition that VC Joseph was the only Alaska Native serving at the executive level at UAF at that time.

Educational philosophies explicitly stated in the grant stressed the importance of culturally responsive teaching, creation of a sense of shared power and authority in the classroom, a co-learner orientation toward classroom teaching, and an explicit anti-racist stance in classroom pedagogy. Key grant objectives required critical facilitation and management of a new conceptual Indigenous framework; this included design of the cultural mentoring and induction services model by project staff and partners. During this process, the Alaska Native educators and Elders reflected on mentoring processes in Western classroom contexts. Mentoring/teaching comes naturally to these educators and Elders; however, adapting their philosophies and activities into a Western framework was often challenging in negotiating two, often conflicting, knowledge and value systems.

SOE programs serve a significant population of Alaska Native students via distance education - and many of the rural areas of the state are "off the road system." Project staff, some students, and a few Alaska Native educators were based in Fairbanks; however, many 
partners, students, and interns were based outside of Fairbanks (and off the road system). Communication with participants required regular phone calls, email, postal mail, faxes, and audio and video conferencing. Other grant-related challenges included a limited travel budget that did not allow partners to meet more than once a year for a face-to-face meeting; more funding was needed for face-to-face strategic planning, especially considering partners' responsibilities to participate in the "refinement of the teacher preparation programs" (as stated in consortia agreements).

Somewhat separate from the cultural mentoring aspects of the grant, although related to student success and completion, project staff worked to develop Praxis study sessions in close collaboration with the Interior-Aleutians Campus (part of CRCD). Praxis is a national testing instrument - and in the case of ANTPP participants, attaining a passing score was critical for progressing to their internship or student teaching year. Alaska's Department of Education sets the passing scores for Praxis - these "passing score" benchmarks are some of the highest in the U.S. Thus, the test functions as another "gatekeeper" for Alaska Native pre-service teachers.

Additional project staff responsibilities included advising students throughout their participation in the grant and in their pre-service UAF SOE program, for example, tutoring in Western educational concepts during their core education courses. Also, the staff advocated for ANTPP participants throughout their participation in the grant, for example, in the case of extended absences to attend funerals for family members or to participate in active student officer roles in the Alaska Native Education Student Association (ANESA).

Prior to beginning cultural mentoring activities for students, consortium partners' roles and responsibilities needed clarification, and a consensus on how to proceed. Partners, with the exception of UAF SOE, were scattered across Alaska and staff and partners were limited to yearly face-to-face meeting. Challenges faced by the Alaska Native teacher organizations as consortium partners included their "separate status" in terms of university affiliation; also, during the course of this project, these associations did not have core staff or sufficient funding to fully maintain their organizations. Carpluk knew and had worked with many of the Alaska Native educators on a statewide basis and documented the early development of these organizations in her master's project (1997). As well, she had close contacts at the College of Rural and Community Development rural campuses. Carpluk had also worked closely with SOE faculty during past projects and was often called upon to serve as a guest lecturer in Alaska Native and cross-cultural communication courses. As such, she was able to effectively coordinate audio conference meetings among the partners and facilitate collaborative decision-making in designing the new cultural components for ANTPP. Through this initial collaborative, community-based process, partners and staff decided on key characteristics of cultural mentoring for all project participants, and induction services for new (first year) Alaska Native teachers. These activities were key to developing a new paradigm for management and leadership within the context of a federal grant-funded project housed within a Western institution.

A third critical component—-the Indigenous Education Institute-was piloted in 2009 
and continued until 2011. The institute was three days in length with the primary purpose of connecting and engaging the pre-service Alaska Native students with Elders and seasoned/ veteran Alaska Native educators. Activities facilitated by the educators and Elders connected Indigenous perspectives on pedagogy, culture-based curriculum development, and culturally sustaining pedagogy. Many of our institute faculty had over twenty years of experience in education at all levels, Western and Indigenous, and most importantly shared how they refined or totally adapted their Western teacher preparation training to teaching from Indigenous perspectives. Participants were particularly interested in culturally appropriate reading strategies; these sessions were facilitated by veteran teachers who had previously developed a master's level course for the UAF Center for Cross-Cultural Studies - "Critiquing Children's Literature from an Indigenous Perspective." Facilitators and Elders also discussed authentic methods of engaging the Alaska Standards for Culturally Responsive Schools (www.unkn.uaf. edu). ${ }^{6}$ In an institute evaluation, the following student's comments reflect her perspectives on the value of these engagements, while also indirectly referencing missing elements in preservice preparation:

The knowledge that the older teachers could provide, and the ones that have gone through it before us. That's something that I really appreciate about this program, you get to talk to other teachers who have been through what you are expected to do to, and encountered things that you anticipate encountering, and they give you their insights, what to do, what to expect (personal communication).

Student comments, from institute evaluations and interview data, reveal a deep appreciation for these exchanges. At SOE, most faculty are non-Native (only two are Alaska Native), and few have extensive experiences teaching Alaska Native students in rural settings. After listening to the veteran teachers describe their experiences of adapting from a Western teacher preparation setting into an Alaska Native teaching context, the following student specifically refers to the "enrich[ed]" learning environment provided by the project:

I am so grateful that [ANTPP is] here. It's something that, especially the connections we have with the other teachers, who maybe didn't have an ANTPP. A lot of their stories, some are funny, some are sad, and some are frustrating, but we make it, those experiences can enrich our learning (personal communication).

A first-year teacher commented specifically on the storytelling and cultural values sessions, observing that "another part of her brain opened up" — a telling statement that reflects, to a certain extent, teacher preparation's disengagement with Alaska Native and Indigenous communities and pedagogies:

I must say that this is another great day in the life of this still new teacher. I feel like my

\footnotetext{
6 See also the State of Alaska's "Guide to Implementing the Cultural Standards."
} 
head just expanded or another part of my brain opened up and information filled it. It is such a good feeling to know that we have such amazing role models. I am so thankful that and are here to encourage us and share their wealth of Indigenous teacher knowledge...I think that it is so cool how the stories are connected to the values and that you can use them to teach so many different things. I am definitely going to use story telling in my classroom... what they shared gives me encouragement to learn more and use it in the classroom... I am so encouraged to do more with the Alaska Native Values posters. I will surely hang them with pride and a better understanding of what they represent. Today had such a positive atmosphere, and it was exactly what I looked forward to coming into this Institute (personal communication)

\section{“Alaska Native Teacher Preparation Remains as a Site of Negotiation and Struggle" (Villegas \& Faircloth, 2010)}

Carpluk's interest and passion, in the last thirty years working in Alaska Native education, has been in the support of Alaska Native students interested in becoming teachers. Through this evolving work, the development of a more sustainable and comprehensive model remains a necessity considering the "revolving door" aspects of federal, state and private grants. There is scant evidence of sustainable impact of these grants on the preparation of preservice Alaska Native students and continued community engagement. ANTPP staff were concerned that project activities remained peripheral to an already established program, in which the AI/AN students were required to participate in activities and events beyond their other requirements within the teacher certification program. Institute participation and deeper levels of engagement with community could have benefitted all the pre-service teachers, not just the AI/AN students. As with other grant-funded projects, when the grant ended, so did everything else: Carpluk and project partners were not offered continuing or associated positions at SOE; as well, the expertise in Alaska Native education, a uniquely designed cultural mentoring model, and the yearly Indigenous Education Institute were discontinued.

As a reminder we re-iterate our "community engagement" questions presented earlier:

- What does it mean to engage community in higher education?

- How are collaboration and engagement defined, and by whom?

- What are the benefits of collaborative work with communities? Are collaborative efforts a "one-way street" or an authentic sharing of time and resources that provides benefits beyond the entities involved?

The creators of ANTPP and project staff did seek to engage Alaska Native communities in pre-service teacher education, and were successful on a number of levels. However, tsome faculty and program leadership were unwilling to support, in many instances, initiatives by project staff in support of the Alaska Native pre-service teachers. In one instance, a student was publicly "scolded" for missing one class because she had planned to attend an Alaska 
Native student teacher meeting with the Alaska Commissioner of Education. Other obstacles included SOE faculty resistance to student travel to attend educational conferences, including the state-sponsored Bilingual Multicultural Educational Equity Conference. With advocacy by project staff, a few students were able to attend education conferences and extend their network among Alaska Native teachers statewide: "at BMEEC we were surrounded by Alaska Native teachers from different backgrounds; we felt empowered. We have the encouragement to keep going from Alaska Native mentors" (personal communication).

The Alaska Native project communities that included Elders, students, and educators enacted educational theory and models--culturally responsive, place-based education, and culturally based education-very differently than their Western counterparts. As Carpluk notes,

many concepts in our own Indigenous languages/cultural worldviews do not translate similarly into English. We teach with spirituality as the core and the Western framework does not, creating conflict and uncomfortable situations for our students. Many of our students have very strong cultural identities and if they have to negotiate or adapt to a different worldview in their pre-service program, they need strong guidance and mentoring from our Alaska Native educators, faculty and Elders to affirm and valid their situations.

Carpluk's comments and observations, drawn from a lifetime of supporting educational initiatives for Alaska Native peoples, were echoed by several of the ANTPP participants, including one young woman who courageously commented:

I say we need culturally responsible professors. We need them [to] take consideration of the hours we put into our communities. We need them to understand our families are much larger than the traditional Western family. When one is injured in our community we [are] all affected. We need them to come in an observe us, and see what is working, not judge us by a few words put on paper.

In their final report, project evaluators (Villegas \& Faircloth, 2012) drafted a powerful set of recommendations addressed to the SOE; these recommendations reflected the responsibilities of consortium partners to refine programs in support of Alaska Native students. The evaluation report was shared among consortium partners, and also with the SOE dean and UAF provost. Summary quotes from their four major recommendations are shared below:

First, it is essential that university leaders take responsibility for progressing the development of Alaska Native teachers. It is not enough to acknowledge a commitment to education of Alaska Native peoples without setting clear, measurable goals to enact this commitment for which the university can be held accountable. As such, we recommend that the University of Alaska Fairbanks set annual and five-year targets around the number of Alaska Native teachers it will graduate and place and

Engaged Scholar Journal: Community-Engaged Research, Teaching, and Learning 
make these targets a matter of public record. (p. 20)

Second, it has come to our attention that a rift has recently developed between the main UAF School of Education teacher preparation program and some or all of the rural campuses. Given the rural nature of many Alaska Native schools and communities, it is critical that these entities come together to ensure teacher preparation candidates have ample opportunities and supports to engage in preparation and training at both the main and rural campuses, as appropriate. (p. 21)

Third, we recommend that Alaska Native educators continue to foster cross-community networks in order to share insights and resources and facilitate intergenerational mentoring that is essential to the success of Alaska Native teachers. Organizations like the Alaska Native Educators Association and regional associations of Alaska Natives (e.g., the Association of Interior Native Educators) must be encouraged to create opportunities for Alaska Native educators to come together and to advocate on behalf of Alaska Native teachers with university and state entities. (p. 21)

Fourth, state agencies involved with teacher development need to acknowledge and involve Alaska Native master teachers in planning accreditation, mentorship, and funding initiatives. It is clear that in order to recruit, graduate, and retain Alaska Native teachers, systemic change is required. There are Alaska Native teachers of a sufficient number across the state who could offer invaluable insight about what it will take to grow their ranks. Yet, they are not consulted as part of policy discussions. (p. 21)

These recommendations have yet to be attended to in substantive ways at our institution, although they are referenced in several reports. "Alaska's university for Alaska's schools" (Hill et. al., 2013), presents "Initiatives to Increase the Number of Alaska Native Educators" (p. 7):

The Schools and College of Education at the University of Alaska (UA) have a strong commitment to the preparation of Alaska Native and Native Alaskan students for the teaching field. This is supported by multiple program delivery formats including traditional on-site face to-face teaching, e-learning formats incorporating many advanced tools, summer institutes where on-site experiences help build collegial relationships and on-site visits. For example, since 1972 UAF has offered a full BA in Elementary Education degree for students who are in rural communities and who want to stay in rural communities. Nearly all of the students who complete a degree while in their own villages stay and teach in their community or region. UAF also has a fulltime Rural Advisor position to support the rural students in their programs. (p. 7) 
The 2011 Teacher Education Plan (referenced in Hill et al., 2013) includes the following recommendations (p. 31-32) regarding "rural and Native education":

- Stronger collaboration with indigenous organizations to change rural teacher preparation;

- Promote cross-cultural studies of Alaska Native culture, history, and legal status;

- Use, expand, improve UA capacity to reach out to rural population through both face to face and enhanced distance media;

- Integrate traditional knowledge systems into curricula; pair traditional values with western values;

- Recruit and education [sic] more Alaska Native and other minority teachers;

- Build knowledge of Native community, culture, and history through partnership with schools.

These reports are encouraging since ANTPP evaluation recommendations are at least addressed, albeit at a surface level; however, the methods through which these goals might be achieved are not examined in any depth. Recruitment and course delivery enhanced "capacities" are useful to Alaska Native students when curricula, methods and faculty are appropriate to Alaska Native contexts. Authentic, non-appropriating integration of "traditional knowledge systems into curricula" needs careful planning and collaboration with Native communities. ANTPP provided a model that addressed all these recommendations and established a "strong collaboration with Indigenous organizations" resulting in specific recommendations to "rural teacher preparation." ANTPP's collaborative initiatives with Alaska Native communities of educators and Elders engaged culturally relevant and sustaining pedagogies in unique ways to nurture Alaska Native pre-service teachers.

\section{Indigenous Communities in Higher Education: A Sacred Learning Landscape}

In their article "Performing decolonization: Lessons learned from Indigenous youth, teachers and leaders' engagement with critical Indigenous pedagogy," Garcia and Shirley (2012) frame education as a "sacred learning landscape," emphasizing the roles of institutions and teachers in nurturing critical consciousness and "origins of place" (pp. 77-78). The learning landscape currently occupied by UAF has been an Indigenous space and Alaska Native community place for millennia:

The late Traditional Chief Peter John of Tanana Chiefs Conference ${ }^{7}$ of interior Alaska said, "Our people used to come to this hill to pick Troth...Troth Yeddha' was important, a meeting place. The grandfathers used to come to talk and give advice to one another about what they were going to do. When they learned this place would be used for a school, the university, they came here one last time, to decide what they should do. They decided that the school would be good and would carry on a very similar traditional use of this hill--a place where good thinking and working together

\footnotetext{
7 Tanana Chiefs Conference is a consortium of 42 Athabascan tribal governments in interior Alaska.
} 
would happen...They were also giving a blessing to their grandchildren who would be part of the new school (University of Alaska Fairbanks, 2012).

In describing the gifting of Troth Yeddha' to the then Territory of Alaska, the Tanana Dena claim an Indigenous pedagogy of place - a hope that "good thinking and working together" will continue and that their grandchildren will be included and appropriately served by this new school. Chief John's words serve as an example of "learning relationships in context" as described by Tewa scholar Cajete (2000, p. 183), both the relationship of UAF to the land, or physical place, as well as the pedagogical place envisioned by the Dena communities.

Both UAF and the University of Alaska (UA) Statewide offices are located on Troth Yeddha'. If the system seeks to "build knowledge of Native community, culture, and history," the institution needs to actively engage this place in public policy documents, reports, programs, and curricula. This is not currently the case in terms of UAF's public "face" and institutional discourse. In our concluding comments below we discuss UA and UAF policy statements that reference responsibilities to Alaska Native peoples.

\section{Concluding Comments}

In "Ancient wisdom, modern science" (Boyer, 2010) discusses the significance of Indigenous knowledge[s] including in tribally controlled colleges:

I believe we are performing acts of decolonization by giving our students access to their tribal knowledge. We are adding experiences and knowledge back rather than taking something away from our students or leaving them with a vacant space. We are helping students relearn their personal and community history. We are helping them regain their connections to the land. (pp. 27-28)

UAF is not classified as a tribal college as such; however, it has a significant percentage of Indigenous students, and publicly stated responsibilities to Alaska Native students and communities. Core themes within UAF's strategic plan include a commitment to "incorporate traditional and local knowledge more fully in appropriate curricula at every level from college preparation to graduate programs" (p. 3) and "double the number of Alaska Native graduate students" (University of Alaska Fairbanks, undated, p. 5). UAF's academic plan highlights the institution's pledge to provide "service to rural and Alaska Native peoples... as central to the strategic direction of UAF" (p. 1), as well as fostering "the success of Alaska Native students and research concerning Alaska Native peoples, including documentation and preservation of languages and culture" (University of Alaska Fairbanks, 2015, p. 2).

"Shaping Alaska's Future" (SAF) (University of Alaska Fairbanks, 2014) was published in 2014, as a strategic directions initiative designed to shape policy at each of the major administrative units and their affiliated rural campuses. Key statements referencing Alaska Native peoples, cultures, languages and knowledge include: 
- UA recruitment, retention and graduation rates are low, especially for disadvantaged and minority populations and for Alaska Natives. Effect: UA graduates reflect the diversity of Alaska (University of Alaska, 2014, p. 7).

- Some Alaska Native languages and cultural traditions are endangered. Many communities do not have sufficient resources to safeguard and nurture culture and the arts, so UA plays a vital role in preserving and advancing this knowledge and these traditions. Effect: UA is a major center of culture and the arts in Alaska and is a center of excellence for Alaska Native and indigenous research and scholarship (University of Alaska, 2014, p. 13).

- Circumpolar communities are experiencing rapid social and economic transformation...These communities need research-based and indigenous knowledge in order to adapt. UA has the expertise to assist these communities, and to do so must effectively communicate with those who need it...Effect: Alaskans and their communities use research-based information, enriched by traditional knowledge, to successfully adapt to change (University of Alaska, 2014, p. 13).

There are a number of problematic orientations in the SAF document: these include deficit assumptions regarding Alaska Native people's abilities to maintain their cultures and languages and the overt hierarchal separation of "research-based [knowledge]" and "Indigenous knowledge." In any case, fulfilling these commitments continues to be a decolonization challenge without adequate numbers of Indigenous faculty who can shape recruitment, teaching, research, and service policies with and for Alaska Native communities. The University of Alaska Fairbanks has a significant number of Alaska Native students-18.5\% as of Fall 2014 -however, Indigenous faculty number have never exceeded 5\% in terms of total faculty numbers. And this percentage is ambiguous because there are several different categories of faculty at UAF including permanent (tenured) faculty, those eligible for a permanent position (tenure-track) and those under term/temporary contracts.

In closing, we propose an engagement in higher education with Grosfoguel's (2012) notion of a "pluri-versity"; that is, a critical, decolonized orientation necessary to authentic, collaborative engagement between Indigenous communities and Western institutions.

Not a uni-versity (where one epistemology defines for the rest the questions and the answers to produce a colonial, uni-versal social science and humanities) but a pluriversity (where epistemic diversity is institutionally incorporated into necessary interepistemic dialogues in order to produce decolonial, pluriversal social sciences and humanities. (p. 84) 


\section{About the Authors}

Ac'aralek Lolly Sheppard Carpluk (Yup'ik) was born and raised in Mountain Village, Alaska. Her Yup'ik upbringing and perspective are continually supported and nurtured by a large extended family. Her formal Western education began in an elementary school in Mountain Village. Carpluk went on to attend both Mt. Edgecumbe and St. Mary's Catholic high schools, and received a BA in sociology, an elementary and secondary teaching certification, and a Master's degree in education, all from the University of Alaska Fairbanks (UAF). The majority of her work experience has been in education. Carpluk has served a variety of committees, including the Native Educators' Conference Planning Committee, the Native Educators' Advisory Committee to the Commissioner of Education, Honoring Alaska's Indigenous Literatures Committee, and the University of Alaska Fairbanks Chancellor's Advisory Committee on Native Education.

Beth Ginondidoy Leonard (Deg Hitâ'an Dena/Athabascan) (corresponding author) is an enrolled member of the Shageluk Tribe of Alaska. Leonard earned her PhD from the University of Alaska Fairbanks (UAF) in 2007 in the Interdisciplinary Program with a focus on cross-cultural and Alaska Native studies. In 2012 Leonard joined the faculty of Cross-Cultural Studies (CCS) at UAF and works closely with graduate students in the CCS master's and Indigenous Studies $\mathrm{PhD}$ programs. Leonard's research interests include Indigenous pedagogies, Indigenous teacher preparation, and Athabascan oral traditions and languages. In 2014 she completed a Fulbright US Core research and teaching scholarship at Te Kawa a MÄui-School of MÄori Studies, Victoria University of Wellington. Email: brleonard@alaska.edu

\section{References}

Alaska Native Knowledge Network. 1998. Alaska standards for culturally responsive schools. Retrieved from http://www.ankn.uaf.edu/publications/standards.html

Au, W. (2014). Retbinking multicultural education: Teaching for racial and cultural justice (2nd ed.). Milwaukee, WI: Rethinking Multicultural Education.

Barnhardt, R. (2002). Domestication of the ivory tower: Institutional adaptation to cultural distance. Anthropology and Education Quarterly, 33(2), 238-249.

Battiste, M. (2013). Decolonizing education: Nourishing the learning spirit. Saskatoon, SK, Canada: Purich Publishing Limited.

Brayboy, B. M. J., Fann, A. J., Castagno, A. E., \& Solyom. (2012). Postsecondary education for American Indian and Alaska Natives: Higher education for nation building and self-determination. San Francisco: Jossey-Bass. 
Brayboy, B. M. J. (2005). Toward a tribal critical race theory in education. The Urban Review, 37(5), 425446.

Castagno, A. E. (2012). "They prepared me to be a teacher, but not a culturally responsive Navajo teacher for Navajo kids": A tribal critical race theory analysis of an Indigenous teacher preparation program. Journal of American Indian Education, 51(1), 3-21.

Carpluk, L. (1997). Contemporary needs to the Native teachers: The formation of Alaska Native teacher associations in Alaska. (Master's Project). University of Alaska Fairbanks, Fairbanks, AK. Retrieved from http://ankn.uaf.edu/Curriculum/Masters_Projects/Carpluk/

Cornell, S. \& Kalt, J. P. (2010). American Indian self-determination: The political economy of a successful policy. The Harvard Project on American Indian Economic Development. Retrieved from https:/ / dash. harvard.edu/handle/1/4553307

Delpit, L. (2006). Otherpeople's children: Cultural conflict in the classroom. New York: The New Press.

Demmert, W., \& Towner, J. C. (2003). A review of the research literature on the influences of culturally based education on the academic performance of Native American students. Portland, OR: Northwest Regional Educational Laboratory.

Garcia, J., \& Shirley, V. (2012). Performing decolonization: Lessons learned from Indigenous youth, teachers and leaderss engagement with critical Indigenous pedagogy. Journal of Curriculum Theorizing, 28(2), 76-91.

Gay, G., \& Kirkland, K. (2003). Developing cultural critical consciousness and self-reflection in preservice teacher education. Theory into Practice, 42(3), 181-187.

Gilmore, P., Smith, D. M., \& Kairaiuak, A. L. (2004). Resisting diversity: An Alaskan case of institutional struggle. In M. Fine, L. Weis, L. P. Pruitt, \& A. Burns (Eds.), Off white: Readings on power, privilege and resistance (pp. 273-283). New York: Routledge.

Grosfoguel, R. (2012). The dilemmas of ethnic studies in the United States: Between liberal multiculturalism, identity politics, disciplinary colonization, and decolonial epistemologies. Human Architecture: Journal of the Sociology of Self-Knowledge. 10(1), 81-89.

Hill, A., \& Hirshberg, D. (2013). Alaska teacher turnover, supply, and demand: 2013 bighlights. Anchorage, AK: Center for Alaska Education Policy Research University of Alaska Anchorage.

Kawagley, A. O. (2006). A Yupiaq worldview: A pathway to ecology and spirit. Long Grove, IL: Waveland Press, Inc.

Ladson-Billings, G. (1995). Toward a theory of culturally relevant pedagogy. American Educational Research Journal, 32(3), 465-491.

Leary, A., Tetpon, B., Hirshberg, D., \& Hill, A. (2014). Alaska Native-focused teacher preparation programs. Anchorage, AK: University of Alaska Anchorage Center for Alaska Education Policy Research.

Leonard, B. (2013). Indigenous pedagogies in the oral traditions of Belle Deacon. Journal of American Indian Education, 52(3), 3-20.

Lipka, J. et. al. (1998). Transforming the culture of schools: Yup'ik Eskimo examples. Mahwah, NJ: Lawrence Erhlbaum Associates.

Madsen, E. \& Brayboy, B. (2007). The Alaska Native teacher preparation project. Unpublished Office of Indian Education grant proposal. University of Alaska Fairbanks.

Ongtooguk, P. (2000). Aspects of traditional Inupiat education. Sharing Our Pathways, 5(4), 8-12.

Paris, D. (2012). Culturally sustaining pedagogy: A needed change in stance, terminology, and practice. Educational Researcher, 41(3), 93-97. 
St. Denis, V. (1992). Community-based participatory research: Aspects of the concept relevant for practice. Native Studies Review, 8(2), 51-74.

University of Alaska Fairbanks. (2012). University of Alaska Fairbanks Student Learning Outcomes Assessment Plan Bachelor of Arts in Elementary Education May, 2012 (Revised in 2006). Retrieved from http://www.uaf.edu/files/provost/EducationElementaryBAPlan2012.pdf

University of Alaska Fairbanks. (2012) Troth Yeddha'. Retrieved from http://www.uaf.edu/catalog/ current/overview/troth_yeddha.html

University of Alaska Fairbanks. (2013). Welcome to the UAF School of Education. Retrieved from https:// sites.google.com/a/alaska.edu/soe-home/

University of Alaska Fairbanks. (2014). Shaping Alaska's future. Retrieved from https://www.alaska. edu/files/shapingalaskasfuture/SAF-FINAL.pdf

University of Alaska Fairbanks. (2015). Academic plan. Retrieved from http://uaf.edu/provost/ general-information/academic-plan/

Villegas, M. \& Faircloth, S. (2011). Alaska Native Teacher Preparation Project-Year 2 Evaluation Report.

Villegas, M. \& Faircloth, S. (2012). Alaska Native Teacher Preparation Project-Year 3 Evaluation Report.

Wilson, S. (2009). Research is ceremony: Indigenous research methods. Black Point, Nova Scotia: Fernwood Publishing. 